\title{
ON THE OSMOTIC PRESSURE OF CERTAIN ETHER SOLUTIONS AND ITS RELATION TO BOYLE- VAN'T HOFF'S LAW.
}

By H. M. Goodwin and George K. Burgess.

T $\mathrm{N}$ a recent article on "The Determination of Osmotic Pressure by Means of Vapor Pressure Measurements" 1 Noyes and Abbot have shown how the osmotic pressure of a solution may be calculated from the specific gravity of the solvent, the relation of its molecular volume in the vapor state to pressure, and the vapor pressure of the solution. A method was worked out for determining the last of these quantities and measurements were made on solutions of naphthalene and of azobenzene in ether, from which the osmotic pressure was computed and the validity of the BoyleVan't Hoff law tested for solutions varying in concentration from about one per cent. to twenty-five per cent. Ether was used as solvent at $12.90^{\circ} \mathrm{C}$. and under reduced pressure, $330.48 \mathrm{~mm}$., in order that the data of Ramsay and Young on the specific volume of its unsaturated vapor might be available in the computation.

The main results of the experimental part of this investigation are shown in the following abbreviated table, in which $P$ is the osmotic pressure of the solution in kilograms per square centimeter and $C$ the concentration expressed as mols per liter of solution.

\begin{tabular}{c|c|c||c|c|c}
\hline \hline \multicolumn{3}{|c|}{ Naphthalene. } & \multicolumn{3}{c}{ Azobenzene. } \\
\hline \multirow{2}{*}{$P$} & $C$ & $\begin{array}{c}P \\
C\end{array}$ & $P$ & $C$ & $P$ \\
& & & & $C$ \\
\hline 1.562 & 0.0559 & 27.93 & 0.958 & 0.0393 & 24.35 \\
6.875 & 0.2727 & 25.21 & 4.620 & 0.1922 & 24.04 \\
12.87 & 0.5286 & 24.35 & 8.858 & 0.3733 & 23.73 \\
23.79 & 0.9978 & 23.84 & 16.71 & 0.7055 & 23.66 \\
27.80 & 1.172 & 23.73 & 19.62 & 0.8289 & 23.67 \\
\hline \hline
\end{tabular}

1 Zeit. für Phys. Chem., 23, 56, 1897. 
The theoretical value of $P / C$ or $P V$ ( $V$ being the volume occupied by one molecular weight) for hydrogen gas at $\mathrm{I} 2.90^{\circ}$ and expressed in the same units (kilogram, liters) is 24.27 , from which it is seen by inspection of the columns containingt he values of $P / C$, that in the case of azobenzene the proportionality between osmotic pressure and concentration, even to great concentrations, is very striking. In the case of naphthalene the proportionality is not so exact, the value $P / C$ or $P V$ diminishing some $16 \%$ with increasing concentration, or, in other words, deviating from Boyle's law in the same direction as the more compressible gases.

Although the estimated error in the case of the dilutest solutions was about $4 \%$, the authors did not lay much weight on the results for these solutions, and were inclined to attribute the anomalous behavior of naphthalene to experimental error rather than to a real deviation from the gas law, especially as it was for dilute solutions of all others that one would naturally expect the relation to hold most exactly.

It was to further test this relation that we undertook the following work, the authors of the mentioned paper being obliged to discontinue further work along this line. Although practically the same experimental method has been employed, it was found necessary to rebuild the greater part of the apparatus, so that the following results can be regarded as entirely independent of the preceding as far as possible instrumental errors are concerned.

\section{Principle of Method.}

For convenience a brief recapitulation of the method may not be out of place here.

The osmotic pressure $P$ of a solution is easily shown to be given by the integral ${ }^{1}$

$$
P=\frac{s_{0}}{M} \int_{p}^{p_{0}} i d p
$$

where $s_{0}$ is the specific gravity and $M$ the molecular weight of the solvent, $v$ the molecular volume of the vapor, $p_{0}$ the vapor pressure

' Here the compressibility of the solvent, and the diminution in vapor pressure of the solution, compared with the total osmotic pressure, are assumed negligible. 
of the solvent, and $p$ that of the solution. In order to integrate this equation it is necessary to express $v^{\prime}$ as a function of $p$. Unfortunately, exact data for this purpose are very meager (unless the gas laws be assumed), that furnished by the investigations of Ramsay and Young being the most reliable. Hence the choice of solvents was restricted to those for which an empirical relation between the specific volume of unsaturated vapor and the pressure had been established. We chose ether at $12.90^{\circ}$ and $330.48 \mathrm{~mm}$. pressure under which conditions Ramsay and Young worked, ${ }^{1}$ for the same reasons as did Noyes and Abbot. We had hoped to extend the experiments also to $50^{\circ}$, but the difficulties involved in working with the apparatus at pressures greater than an atmosphere have prevented our doing so thus far.

The relative density $\delta$ of ether vapor referred to hydrogen at $12.90^{\circ}$ is given by the equation ${ }^{2}$

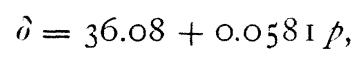

where $p$ is the pressure in centimeters. Hence

$$
v=\frac{M}{w p o}=\frac{M}{w p(a+b p)}
$$

where $w$ is the weight of one cubic centimeter of hydrogen at I $2.9^{\circ} \mathrm{C}$. and $\mathrm{I} \mathrm{cm}$. pressure, and $a$ and $b$ the numerical constants in the above equation for $\partial$.

Integrating ( $\mathrm{I}$ ) by means of this relation we obtain

$$
P=\frac{s_{0}}{a w} \ln \frac{p_{0}(a+b p)}{p\left(a+b p_{0}\right)}
$$

from which $P$ can be computed when $p_{0}, p$ and $s_{0}$ are known. In order to obtain from the percentage composition by weight of the solution the volume occupied by one molecular weight of the dissolved substance, it is necessary to know in addition the specific gravity of the solution.

\footnotetext{
${ }^{1}$ Philosophical Transactions, 178,63 .

2 Noyes and Abbot, Zeit. für Phys. Chem., 23, 72, 1897 .
} 


\section{Apparatus.}

The method employed for measuring the vapor pressure was a dynamical one, first suggested by Raoult, ${ }^{1}$ but apparently discarded by him as being less convenient than the statical method. It consists in causing the solution to boil at the same temperature as the pure solvent, the external pressure being adjusted until this is effected. The diminution of pressure necessary to effect this is the desired lowering of the vapor pressure of the solution. For details of the apparatus and method reference must be made to the paper of Noyes and Abbot. For convenience and clearness the main features only will be mentioned here. The temperature of the boiling solution was indicated by means of a platinum resistance thermometer of about I $00 \mathrm{ohms}$ resistance, which forced one arm of a Wheatstone bridge. The three other arms of the bridge consisted of coils of manganine wire of about $100 \mathrm{ohms}$ resistance, maintained at a constant temperature in a thermostat. A sensitive reflecting galvanometer was employed for indicating a balance in the bridge. It was capable of indicating with certainty a change in temperature of $0.00 \mathrm{I}^{\circ}$ of the platinum thermometer, this temperature variation producing a deflection of $1.8 \mathrm{~mm}$. on the scale. Thermoelectric disturbances were compensated by means of an adjustable counter electromotive force in the galvanometer circuit. The pressures were read by means of a cathetometer, reading to $0.02 \mathrm{~mm}$., on a mercury cistern manometer connected with the boiling flask through five large air reservoirs of equal capacity, which were maintained at constant temperature in the above-mentioned thermostat. The manometer was calibrated against a standard barometer. The boiling flask proper, of about 200 cc., was completely jacketed by an outer boiler in which pure ether was caused to boil at a pressure a few millimeters in excess of that in the boiling flask itself, thus maintaining the temperature of the surroundings within a fraction of a degree of that of the boiling solution.

The whole bridge arrangement was adjusted once for all by placing the platinum resistance thermometer and a primary standard mercury thermometer (calibrated at the Reichsanstalt), reading 
by estimation to $0.005^{\circ}$, side by side in an ether bath brought to exactly $12.90^{\circ}$, while the manganine coils in the thermostat were kept at the temperature at which they were subsequently maintained during a run. The conditions during this fundamental adjustment were brought as near as possible to those under which the actual measurements were made. This adjustment was made by Noyes and Abbot by bringing the pressure in the boiling flask to exactly Ramsay and Young's value $330.48 \mathrm{~mm}$., causing the ether to boil with the resistance thermometer in place, and adjusting the bridge until no deflection was produced by the galvanometer. It seemed to us, however, more desirable to adjust the bridge with the ether and coil at the proper tempirature, than under the conditions of the corresponding pressure.

The procedure in each experiment was as follows: I $25 \mathrm{cc}$. of ether was introduced into the flask by means of a calibrated pipette, and the pressure adjusted by means of a suction pump and conveniently arranged stopcocks until, when the liquid was boiling briskly, no deflection was produced on closing the galvanometer circuit. This gave the vapor pressure $p_{0}$ of the solvent when boiling at $\mathrm{I} 2.90^{\circ} \mathrm{C}$. Weighed portions of the substance in the form of short sticks were then introduced into the ether without opening the apparatus, by the device employed by Abbot. The pressure was then readjusted until again no deflection of the galvanometer was produced, that is, until the solution boiled constantly at the original temperature of the boiling solvent. The mean of at least four independent adjustments of the pressure was taken in each case. The average deviation of the mean was about $0.02 \mathrm{~mm}$. The observed difference of pressure $p_{0}-p$, corrected for temperature and for the variation of level of mercury in the manometer cistern gave the vapor pressure lowering of the solution. The time required to carry through a run at ten different concentrations was from eight to ten hours.

Specific Gravity Measurements.

Duplicate measurements in each case, which checked to 0.1\%, were made as follows: about $75 \mathrm{cc}$. of ether was weighed in a I $00 \mathrm{cc}$. flask with tight fitting stopper, to which a weighed portion 
of the solute was added. The flask was then connected with a drying tube and with a Sprengel-Ostwald pyknometer of $20 \mathrm{cc}$. capacity, which was immersed in water at $0.0^{\circ} \mathrm{C}$. This was filled by forcing the solution into it by blowing through the drying tube. It was then transferred to a bath at $12.90^{\circ} \mathrm{C}$. and the solution brought to the reference mark. To prevent loss of ether due to expansion and evaporation, the ends of the pyknometer were closed with spherical bulbs, one of which was sealed and the other drawn out to a capillary. Weighings were made as quickly as possible.

\section{Preparation of Ether.}

About eight liters of sodium distilled ethyl ether of Kahlbaum's preparation were obtained, and to further purify the product, it was treated as follows: alcohols which may have been present were removed by treating fourteen times with a pure potassium hydrate solution ( $\mathrm{I}$ to 20 ,) in portions of about $300 \mathrm{cc}$. each. The final absence of color in the hydrate which settled out indicated complete removal of any alcohols. In a similar manner the ether was then washed five times with $100 \mathrm{cc}$. portions of water. 500 grams of calcium chloride were added and the mixture allowed to stand three weeks, with frequent agitation, after which the ether was distilled, the first and last portions of $100 \mathrm{cc}$. being discarded. The total time of distillation was twelve hours, divided among three successive days. The temperature on each day was constant to $\mathrm{O}^{\circ}{ }^{\circ} \mathrm{C}$. and was $34.3^{\circ} \mathrm{C}$. at $753 \mathrm{~mm}$., $34.6^{\circ}$ at $766 \mathrm{~mm}$. and $34.3^{\circ}$ at $752 \mathrm{~mm}$. The distillate thus obtained showed practically no effervescence with metallic sodium.

The specific gravity of this ether at $12.90^{\circ}$ was found to be 0.7210 (Noyes and Abbot, $0.7206 ;$ Kopp, 0.721), while its vapor pressure was $33.184 \mathrm{~cm}$. Hg. (Ramsay and Young, $33.048 \mathrm{~cm}$; Noyes and Abbot, $32.990 \mathrm{~cm}$.).

\section{Preparation of Substances Used in Solution.}

The substances used in solution were naphthalene, benzophenone and diphenylamine. The last two were chosen on account of their ready solubility in ether and their very high boiling point, both being over $300^{\circ}$. This is a very essential point, as the vapor pres- 
sure of the dissolved substance is assumed in the calculation to be negligible compared with that of the solvent. All preparations were from Kahlbaum, and their purity was tested by determining the constancy of their freezing points. About $25 \mathrm{cc}$. of each substance was put into a test tube and heated in a sulphuric acid bath until completely liquified. It was then allowed to cool very slowly with constant stirring and the temperature noted until the whole mass had solidified. The freezing points were in each case practically constant so long as any liquid remained, and the substances were therefore considered sufficiently pure. The freezing points were : diphenylamine $53.6 \mathrm{I}^{\circ} \pm 0.04$; benzophenone $48.35^{\circ} \pm 0.02$.

The naphthalene used was a portion of the same product used by Noyes and Abbot. It solidified at a constant temperature of $79.60^{\circ}$.

\section{ExPERIMENTAI Results.}

In Table I. are given the results of the specific gravity measurements. The first column contains the concentrations $K$ (ratio of total weight of substance to weight of solvent) and the second the specific gravity at $12.90^{\circ} \mathrm{C}$. referred to water at $4^{\circ} \mathrm{C}$. A plot was made with these values for each substance, from which the specific gravity at any desired concentration was interpolated. The specific gravities used for the naphthalene solutions were those obtained by Noyes and Abbot.

TABLE I.

\begin{tabular}{c|c||c|c||c|c}
\hline \hline \multicolumn{2}{c||}{$\begin{array}{c}\text { Naphthalene (Noyes } \\
\text { and Abbot). }\end{array}$} & \multicolumn{2}{c||}{ Benzophenone. } & \multicolumn{2}{c}{ Diphenylamine. } \\
\hline $\begin{array}{c}\text { Concentra- } \\
\text { tion K. }\end{array}$ & $\begin{array}{c}\text { Specific } \\
\text { Gravity. }\end{array}$ & $\begin{array}{c}\text { Concentra- } \\
\text { tion K. }\end{array}$ & $\begin{array}{c}\text { Specific } \\
\text { Gravity. }\end{array}$ & $\begin{array}{c}\text { Concentra- } \\
\text { tion K. }\end{array}$ & $\begin{array}{c}\text { Specific } \\
\text { Gravity. }\end{array}$ \\
\hline 0.0514 & 0.7336 & 0.0041 & 0.7212 & 0.0153 & 0.7251 \\
0.0674 & 0.7375 & 0.0214 & 0.7264 & 0.0478 & 0.7357 \\
0.0800 & 0.7418 & 0.0465 & 0.7339 & 0.0708 & 0.7417 \\
0.1392 & 0.7539 & 0.0816 & 0.7437 & 0.1158 & 0.7534 \\
0.1406 & 0.7536 & 0.1062 & 0.7505 & 0.1243 & 0.7544 \\
0.1761 & 0.7617 & 0.1169 & 0.7532 & 0.2217 & 0.7792 \\
0.2243 & 0.7700 & 0.1234 & 0.7554 & & \\
0.2432 & 0.7764 & 0.1852 & 0.7705 & & \\
0.2589 & 0.7766 & 0.2770 & 0.7902 & & \\
0.2699 & 0.7796 & 0.4130 & 0.8165 & & \\
\hline
\end{tabular}


I78 IT. M. GOODWIN AND GEORGE K. BURGESS. [VOL. VII.

TABle II.

Naphthalene.

First SERIES,

Weight of Ether $=89.01$ grams.

\begin{tabular}{|c|c|c|c|c|c|}
\hline $\begin{array}{l}\text { Portion } \\
\text { Number. }\end{array}$ & $\begin{array}{l}\text { Weight of } \\
\text { each Portion } \\
\text { in grams. }\end{array}$ & $\begin{array}{c}\text { Concentra- } \\
\text { tion. }\end{array}$ & $\begin{array}{c}p_{0}-p \\
\text { uncorrected. }\end{array}$ & $\begin{array}{c}p_{n}-p \\
\text { corrected. }\end{array}$ & $\begin{array}{l}\text { Deviation of } \\
\left(\not p_{0}-\not p\right) \\
\text { from curve. }\end{array}$ \\
\hline 1 & 0.595 & 0.006685 & 0.181 & 0.188 & +0.027 \\
\hline 2 & 0.731 & 0.01490 & 0.371 & 0.385 & +0.042 \\
\hline 3 & 0.591 & 0.02154 & 0.513 & 0.532 & +0.051 \\
\hline 4 & 2.036 & 0.04441 & 0.862 & 0.894 & -0.058 \\
\hline 5 & 1.931 & 0.06610 & 1.261 & 1.308 & rejected \\
\hline 6 & 2.690 & 0.09632 & 1.790 & 1.856 & +0.014 \\
\hline 7 & 4.356 & 0.1453 & 2.389 & 2.478 & -0.110 \\
\hline 8 & 4.128 & 0.1916 & 3.097 & 3.211 & -0.036 \\
\hline \multirow{2}{*}{\multicolumn{6}{|c|}{$\begin{array}{l}\text { SECOND SERIEs. } \\
\text { tof Ether }=89.17 \mathrm{grams} \text {. }\end{array}$}} \\
\hline & & & & & \\
\hline 1 & 0.698 & 0.00783 & 0.182 & 0.189 & +0.005 \\
\hline 2 & 0.641 & 0.01502 & 0.292 & 0.303 & -0.039 \\
\hline 3 & 0.978 & 0.02598 & 0.506 & 0.525 & -0.029 \\
\hline 4 & 1.436 & 0.04209 & 0.816 & 0.846 & -0.035 \\
\hline 5 & 2.685 & 0.07221 & 1.324 & 1.373 & -0.054 \\
\hline 6 & 3.079 & 0.1067 & 1.921 & 1.992 & -0.015 \\
\hline 7 & 3.979 & 0.1514 & 2.598 & 2.694 & +0.010 \\
\hline 8 & 3.832 & 0.1944 & 3.182 & 3.299 & +0.014 \\
\hline 9 & 3.954 & 0.2387 & 3.794 & 3.935 & +0.020 \\
\hline
\end{tabular}

Third Series.

Weight of Ether $=88.85$ grams.

\begin{tabular}{l|l|l|l|l|l}
\hline 1 & 0.406 & 0.00457 & 0.103 & 0.107 & -0.003 \\
2 & 0.379 & 0.00883 & 0.184 & 0.190 & -0.021 \\
3 & 0.580 & 0.01536 & 0.333 & 0.345 & -0.005 \\
4 & 0.463 & 0.02057 & 0.506 & 0.525 & rejected \\
5 & 0.707 & 0.02853 & 0.605 & 0.627 & +0.006 \\
6 & 0.976 & 0.03953 & 0.833 & 0.864 & +0.030 \\
7 & 1.523 & 0.05666 & 1.123 & 1.164 & +0.012 \\
\hline
\end{tabular}

Fourth Series.

Weight of Ether $=88.88$ grams .

\begin{tabular}{l|l|l|l|l|l}
\hline & 0.991 & 0.01115 & 0.242 & 0.251 & -0.006 \\
2 & 1.027 & 0.02271 & 0.498 & 0.516 & +0.020 \\
3 & 0.830 & 0.03204 & 0.685 & 0.710 & +0.017 \\
4 & 2.257 & 0.05744 & 1.143 & 1.186 & +0.021 \\
5 & 1.175 & 0.07066 & 1.353 & 1.403 & +0.002 \\
6 & 3.071 & 0.1052 & 1.923 & 1.995 & +0.010 \\
\hline
\end{tabular}


TABLE III.

BENZOPHENONE.

First SERIES.

Weight of Ether $=89.02$ grams.

\begin{tabular}{|c|c|c|c|c|c|}
\hline Portion. & $\begin{array}{l}\text { Weight in } \\
\text { grams. }\end{array}$ & $\begin{array}{c}\text { Concentra- } \\
\text { tion. }\end{array}$ & $\begin{array}{c}p_{0}-p \\
\text { observed. }\end{array}$ & $\begin{array}{c}p_{0}-\not p \\
\text { corrected. }\end{array}$ & $\begin{array}{l}\text { Deviation of } \\
p_{0}-\not \\
\text { from curve. }\end{array}$ \\
\hline 1 & 1.768 & 0.01986 & 0.259 & 0.269 & +0.013 \\
\hline 2 & 2.158 & 0.04410 & 0.554 & 0.575 & +0.022 \\
\hline 3 & 2.271 & 0.06961 & 0.857 & 0.889 & +0.030 \\
\hline 4 & 3.424 & 0.1081 & 1.267 & 1.314 & +0.038 \\
\hline 5 & 2.495 & 0.1361 & 1.561 & 1.619 & +0.015 \\
\hline 6 & 3.558 & 0.1760 & 1.928 & 1.999 & +0.020 \\
\hline 7 & 4.709 & 0.2290 & 2.380 & 2.468 & -0.001 \\
\hline
\end{tabular}

Second Series.

Weight of Ether $=89.04$ grams.

\begin{tabular}{l|l|l|l|l|r}
\hline 1 & 1.058 & 0.01190 & 0.148 & 0.154 & +0.012 \\
2 & 1.728 & 0.03129 & 0.418 & 0.433 & +0.003 \\
3 & 2.400 & 0.05824 & 0.757 & 0.785 & 0.000 \\
4 & 3.757 & 0.1004 & 1.219 & 1.270 & +0.008 \\
5 & 4.441 & 0.1503 & 1.739 & 1.803 & -0.020 \\
6 & 4.816 & 0.2044 & 2.163 & 2.243 & +0.020 \\
7 & 5.434 & 0.2654 & 2.655 & 2.753 & 0.000 \\
\hline
\end{tabular}

THIRD SSRIES.

Weight of Ether $=88.86$ grams.

\begin{tabular}{l|l|l|l|l|l}
\hline 1 & 1.025 & 0.01153 & 0.174 & 0.180 & -0.014 \\
2 & 1.435 & 0.02769 & 0.401 & 0.416 & -0.001 \\
3 & 1.201 & 0.04121 & 0.579 & 0.600 & -0.028 \\
4 & 1.546 & 0.05860 & 0.774 & 0.803 & -0.010 \\
5 & 2.934 & 0.09162 & 1.175 & 1.219 & -0.033 \\
6 & 2.775 & 0.1228 & 1.456 & 1.510 & +0.020 \\
7 & 4.016 & 0.1680 & 1.899 & 1.969 & -0.022 \\
8 & 4.149 & 0.2147 & 2.292 & 2.377 & -0.030 \\
\hline
\end{tabular}

Tables II., III. and IV. contain the observed data on the lowering of the vapor pressure of the solutions and their corresponding concentrations. The first column contains the number of each portion of the dissolved substance; the second, its weight; the third, the concentration $K$ of the solution ; the fourth, the mean of the observed differences of the cathetometer readings in centimeters, 
TABLE IV.

DIPHENYLAMINE.

First SERIES.

Weight of Ether $=88.64$ srams.

\begin{tabular}{c|c|c|c|c|c}
\hline \hline Portion. & $\begin{array}{c}\text { Weight in } \\
\text { grams. }\end{array}$ & $\begin{array}{c}\text { Concentra- } \\
\text { tion }\end{array}$ & $\begin{array}{c}p_{1}-p \\
\text { observed. }\end{array}$ & $\begin{array}{c}p_{0}-p \\
\text { corrected. }\end{array}$ & $\begin{array}{c}\text { Deviation of } \\
p_{0}-p \\
\text { from curve. }\end{array}$ \\
\hline 1 & 1.303 & 0.01469 & 0.224 & 0.232 & +0.025 \\
2 & 0.909 & 0.02496 & 0.398 & 0.413 & +0.015 \\
3 & 1.259 & 0.03917 & 0.626 & 0.649 & -0.002 \\
4 & 1.861 & 0.06016 & 0.905 & 0.938 & +0.018 \\
5 & 2.228 & 0.08529 & 1.266 & 1.310 & 0.000 \\
6 & 3.144 & 0.1208 & 1.727 & 1.791 & 0.000 \\
7 & 3.887 & 0.1646 & 2.287 & 2.372 & -0.020 \\
\hline
\end{tabular}

SeCOND Series.

Weight of Ether $=87.64$ grams.

\begin{tabular}{l|l|l|l|l|l}
\hline 1 & 0.611 & 0.006971 & 0.146 & 0.152 & -0.022 \\
2 & 1.021 & 0.01862 & 0.316 & 0.328 & -0.001 \\
3 & 1.701 & 0.03803 & 0.610 & 0.633 & -0.002 \\
4 & 1.692 & 0.05733 & 0.877 & 0.910 & +0.001 \\
5 & 2.617 & 0.08720 & 1.292 & 1.340 & -0.001 \\
6 & 3.533 & 0.1276 & 1.801 & 1.872 & +0.001 \\
7 & 4.141 & 0.1748 & 2.361 & 2.448 & +0.022 \\
\hline \hline
\end{tabular}

and the fifth, the corrected value obtained by multiplying by 1.037 , the correction factor for the change of level of the mercury in the cistern of the manometer, and reduction to zero degrees.

The data for each solution was plotted on a large scale with values of $p_{0}-p$ as ordinates and $K$ as abscissæ and the best representative curve drawn through the points. From this curve of vapor pressure lowering, the value of $p_{0}-p$ for even concentrations was interpolated. In the case of naphthalene and benzophenone, a residual plot was made on a large scale to ensure no sacrifice $o$ precision of the data. This was obtained by assuming the equation of a straight line approximately representing the data, $i . e .,\left(p_{0}-p\right)$ $=$ const. $\times K$, and finding the difference between the observed values of $p_{0}-p$ and those computed from this equation for given values of the concentration. The best smooth curve representing these differences was then drawn, from which the values of $p_{0}-p$ obtained from the assumed straight line could be corrected by the 
proper amount. It was found that the mean values for the vapor pressure lowering obtained by this method were practically the same as those obtained from a large direct plot, so that in the case of diphenylamine only the latter was used.

In the last column of the above table is given the actual deviation of each observation from the curve taken as best representing all the data for each solution. The average of these deviations for the three solutions investigated is $0.025 \mathrm{~cm}$. for naphthalene, 0.016 $\mathrm{cm}$. for benzophenone, and .0IO cm. for diphenylamine. For some unexplained reason the naphthalene solutions gave repeatedly the least concordant results. A treatment of Noyes and Abbot's data in the same manner as the above gives for the average deviation of all observations on naphthalene (four series), $0.024 \mathrm{~cm}$., and for azobenzene (three series) $0.019 \mathrm{~cm}$. Whether the irregularities presented by solutions of the former substance are due to its greater volatility, we have not been able to determine. The series cannot be regarded as satisfactory for solutions less concentrated than 5 per cent. in which case the error in the vapor pressure lowering is about two per cent. For a Io per cent. solution the error in $p_{0}-p$ is, however, only a little over one per cent. On the other hand, the agreement of the benzophenone and diphenylamine series is seen to be very much more satisfactory.

It should be mentioned that in order to eliminate constant errors as far as possible, the runs on each substance were not made consecutively; the separate runs with benzophenone, for example, were made two weeks apart, with several runs on naphthalene and diphenylamine made in the meantime. The good concordance of results on two of our solutions measured in this manner indicates that the apparatus was at all times in proper adjustment, and that the larger deviations observed with the naphthalene are probably due to variable causes inherent in the solution itself.

In Table $\mathrm{V}$. are given the values of the vapor pressures of the solutions at even concentrations, expressed in centimeters of mercury at $0^{\circ} \mathrm{C}$. These values are obtained by subtracting the lowering $p_{0}-p$, obtained graphically as described above, from 33.184 $\mathrm{cm}$., the mean value of a series of measurements of the vapor pressure of the pure ether used. This value differs by about 0.4 
I82 H. M. GOODWIN AND GEORGE K. BURGESS. [VOL. VII.

per cent. from that given by Ramsay and Young, namely, 33.048. We have thought best to use the observed value of $p_{0}$ in the computation rather than Ramsay and Young's, as it represents the true value of the pressure under the conditions of temperature at which the bridge adjustment was made. From the data in this table the value of the osmotic pressure was computed by formula (2), which reduces for computation to

TABLE V.

\begin{tabular}{|c|c|c|c|c|c|c|}
\hline \multirow{2}{*}{$\begin{array}{l}\text { Concen- } \\
\text { tration. }\end{array}$} & \multicolumn{2}{|c|}{ Naphthalene. } & \multicolumn{2}{|c|}{ Benzophenone. } & \multicolumn{2}{|c|}{ Diphenylamine. } \\
\hline & $\begin{array}{c}\text { Vapor } \\
\text { Pressure. }\end{array}$ & $\begin{array}{l}\text { Specific } \\
\text { Gravity. }\end{array}$ & $\begin{array}{c}\text { Vapor } \\
\text { Pressure. }\end{array}$ & $\begin{array}{l}\text { Specific } \\
\text { Gravity. }\end{array}$ & $\begin{array}{l}\text { Vapor } \\
\text { Pressure. }\end{array}$ & $\begin{array}{l}\text { Specific } \\
\text { Gravity. }\end{array}$ \\
\hline 0.00 & 33.184 & 0.7210 & 33.184 & 0.7210 & 33.184 & 0.7210 \\
\hline .01 & 32.958 & .7232 & 33.039 & .7236 & 33.005 & .7238 \\
\hline .02 & 32.736 & .7258 & 32.899 & .7264 & 32.840 & .7269 \\
\hline .03 & 32.534 & .7283 & 32.763 & .7291 & 32.679 & .7300 \\
\hline .05 & 32.153 & .7330 & 32.502 & .7351 & 32.377 & .7357 \\
\hline .07 & 31.798 & .7376 & 32.254 & .7420 & 32.092 & .7407 \\
\hline .10 & 31.287 & .7443 & 31.911 & .7492 & 31.676 & .7494 \\
\hline .13 & 30.817 & .7512 & 31.604 & .7569 & 31.275 & .7561 \\
\hline .16 & 30.376 & .7578 & 31.312 & .7645 & 30.888 & .7645 \\
\hline .20 & 29.822 & .7663 & 30.958 & .7741 & & \\
\hline .24 & & & 30.552 & .7851 & & \\
\hline
\end{tabular}

$$
P=554300\left[\log _{10} \frac{a+b p}{p}+\overline{\mathrm{I}} .94 \mathrm{IO} 3\right]
$$

by introduction of the numerical value of the constants $a=36.08$; $b=0.0581 ; p_{0}=33.184 ; s_{0}=0.7210 ; w=\frac{0.08987 \times 273 . \mathrm{I}}{286.0 \times 76}$ and the factors 13.60 , the specific gravity of mercury to reduce the pressure to grams, and 2.303, to convert Naperian to Briggs' logarithms.

In Table VI., column five, is given the result of this computation, at concentrations expressed in the following units :

$K$, as previously defined, the fractional concentration by weight. $C_{1}$ the number of gram molecules of solute in one kilogram of solvent (Raoult);

$C_{2}$ the number of gram molecules of solute in one liter of solution (Arrhenius); 

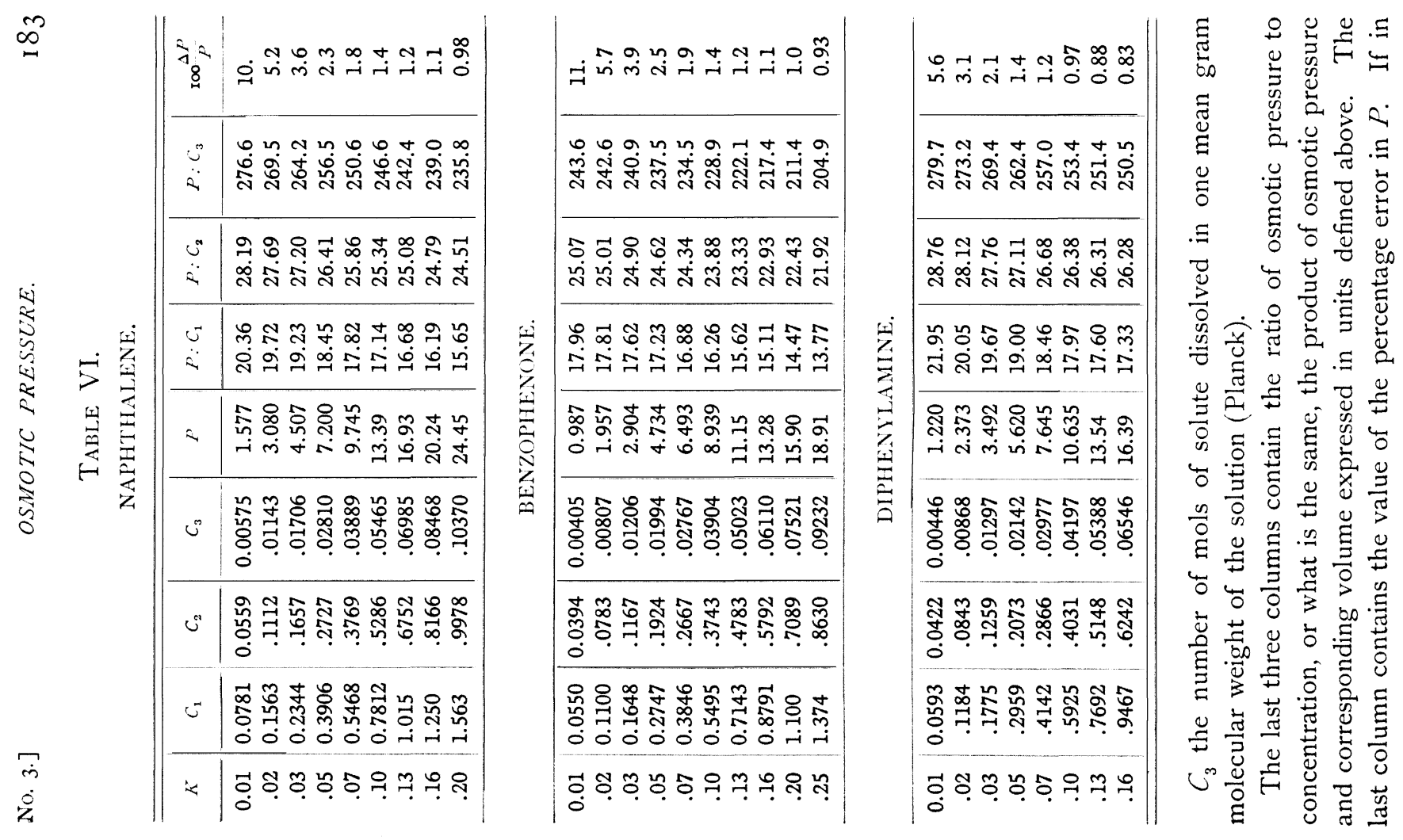
(2) we put $p_{0}-p=\Delta p ; d_{0}=a+b p_{0}$; and $\frac{s_{0}}{w}=$ const., we obtain by a simple transformation and expansion by Maclaurin's theorem $P=$ const. $\times \frac{\mathrm{I}}{d_{0}} \times \frac{\Delta p}{p_{0}}$ approximately, in which $d_{0}, p_{0}$ and $\Delta p$ are the variables to be considered in computing the accuracy of $P$. Hence the fractional error in $P$ is

$$
\frac{\Delta P}{P}=\sqrt{\left(\frac{\partial d_{0}}{d_{0}}\right)^{2}+\left(\frac{\partial \Delta p}{\Delta p}\right)^{2}+\left(\begin{array}{c}
\partial p_{0} \\
p_{0}
\end{array}\right)^{2}} .
$$

The assumption is here made that the error in $s_{0}$ is less than $0.1 \%$ and negligible together with the error in $w$. In computing $\frac{\Delta P}{P}$ the values taken for $\partial(\Delta p)$ are those on pages $178-180 ; \frac{\partial d_{0}}{d_{0}}$ and $\frac{\partial p_{0}}{p_{0}}$ are each taken equal to 0.005 , these values being considered the most probable ones assignable.

It is evident from an inspection of Table VI. that strict proportionality between osmotic pressure and concentration does not hold,

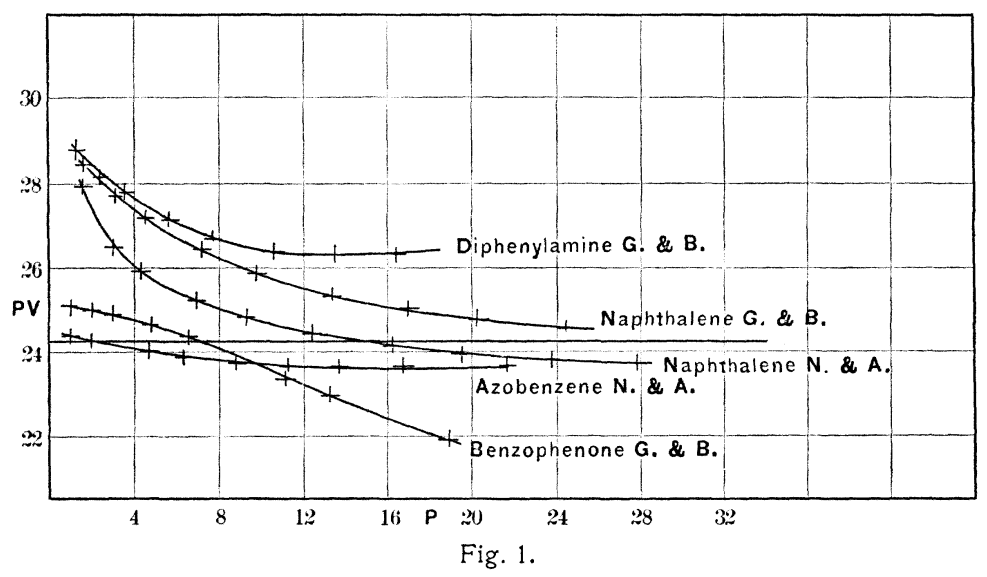

however the concentration be computed. The ratio diminishes in all cases and by different amounts for the different substances. Furthermore, the values of $P \div C_{2}$ or $P V$, where $V$ is the volume occupied by one mol, are not equal for the same cencentrations of 
the different solutions as they should be if each dissolved substance followed the laws of a perfect gas. These relations are more clearly seen by reference to the plot, in which values of $P \div C_{2}=P V$ are plotted as ordinates and $P$ as abscissæ, not only for our solutions but also for those investigated by Noyes and Abbot. The heavy horizontal line at 24.27 represents the corresponding curve for hydrogen gas at the same temperature, $12.90^{\circ} \mathrm{C}$.

Although but little weight can be given to the numerical value of the measurements on the dilute solutions on account of the large experimental error, yet inspection of the curves indicates that none of the substances investigated follows strictly the laws of a perfect gas. Azobenzene approaches very nearly to the ideal condition as already pointed out by Noyes and Abbot. The curves for the other three substances, on the other hand, resemble very markedly those of imperfect gases under pressures at which the effect of molecular attraction preponderates over that of covolume. Thus the decrease in the value of $P V$ for benzophenone is very marked and the curve shows no indication of reaching a minimum even at 20 atmospheres.

The naphthalene curve obtained by us is of practically the same form as that obtained by Noyes and Abbot, but uniformly higher. The cause of this constant discrepancy is not clear; we have been unable to discover any source of constant error in our measurements of this amount. It may be due, in part at least, to the different preparation of ether used, and to the method of making the fundamental adjustment of the apparatus, page I74. The form of the curve, however, is in very satisfactory agreement with the earlier measurements.

Diphenylamine is particularly interesting, as the value of $P V$, after decreasing rapidly at first, apparently reaches a nearly constant value at about eighteen atmospheres, after which it probably increases, ${ }^{1}$ exactly as is the case with imperfect gases under high pressures. The comportment of substances in solution and of imperfect gases would seem to be, from these results, completely analogous in their isothermal relation of pressure and volume. Whereas the general applicability of the $P V=R T$ relation to sub-

${ }^{1}$ An extrapolation of the vapor pressure curve indicates that this would be the case. 
stances in dilute solution has been demonstrated in numerous recent investigations, yet our experiments seem to indicate that this equation is more or less deviated from by different individual solutes, in much the same way as the relation is departed from by imperfect gases, such as nitrous oxide, ammonia, etc., at not too high temperatures and at great pressures.

The fact that in all of the solutions investigated the greatest variations of $P V$ are in the dilutest solutions, whereas, on theoretical grounds, the contrary is to be expected, appears to us to warrant no final conclusions at present in view of the unavoidable large error in measurements of the lowering of the vapor pressure of such dilutions. We hope to be able soon to greatly increase the accuracy of vapor pressure measurements of dilute solution, by a new method, the preliminary results of which give much promise of success.

The fact that the values of $P V$ for the dilute solutions are in all cases greater than 24.27 , the value for hydrogen, is also deserving of notice. This might be explained by a dissociation of the dissolved substances in the dilute solutions. Such an assumpton, however, without at least further confirmation, seems, in view of the nature of the solvent and solutes used, highly improbable.

\section{Conclusion.}

The osmotic pressure of solutions of naphthalene, benozphenone, and diphenylamine in ether at $12.90^{\circ} \mathrm{C}$. was determined from measurements on the vapor pressure of these solutions at concentrations varying from about $0.0 \mathrm{I}$ to $\mathrm{I} . \mathrm{O}$ normal corresponding to osmotic pressures from about one to twenty-five atmospheres. A study of the variation of the product $P V$ with the pressure indicates that none of these substances in solution comports itself like a permanent or perfect gas, but rather like an imperfect or readily compressible gas, as the product unmistakably decreases with increasing pressure. This is very marked in the case of benzophenone and less so with naphthalene; in the case of diphenylamine the product diminishes up to about eighteen atmospheres, when it becomes constant or increases. Azobenzene, investigated by Noyes and Abbot 
approaches, on the other hand, quite nearly to the condition of a perfect gas. It would seem therefore probable, that every substance when in solution has its own characteristic condition equation connecting temperature, osmotic pressure and volume, analogous to every more or less readily compressible gas, even when complications arising from dissociation or polymerization phenomena are, from the nature of the solvent and solute used, highly improbable. Substances analogous to the permanent gases would seem to be the exception rather than the rule.

Massachusetts Institute of Technology, Rogers Laboratory of Physics, May, I898. 